\title{
Biological Control of Insect Pests of Agricultural Crops through Habitat Management Was Discussed
}

\author{
M. S. Akter, S. S. Siddique, R. Momotaz, M. Arifunnahar, K. M. Alam, S. J. Mohiuddin \\ Plant Breeding Division, Bangladesh Agricultural Research Institute, Dhaka, Bangladesh \\ Email: sheuly013@gmail.com
}

How to cite this paper: Akter, M.S., Siddique, S.S., Momotaz, R., Arifunnahar, M., Alam, K.M. and Mohiuddin, S.J. (2019) Biological Control of Insect Pests of Agricultural Crops through Habitat Management Was Discussed. Journal of Agricultural Chemistry and Environment, 8, 1-13. https://doi.org/10.4236/jacen.2019.81001

Received: October 30, 2018

Accepted: December 15, 2018

Published: December 18, 2018

Copyright $\odot 2019$ by authors and Scientific Research Publishing Inc. This work is licensed under the Creative Commons Attribution International License (CC BY 4.0).

http://creativecommons.org/licenses/by/4.0/

\begin{abstract}
Biological control through habitat management leads to sustainable insect pest control. Different types of land composition such as multiple landscapes, patchiness of landscapes enhance the natural enemies which ultimately lead to control of insect pest. Plant characteristics such as flower shape, flower color and blooming period ensures excess food for natural enemies like nectar and pollen. Moreover, some agricultural practices such as tillage, crop rotation, and intercropping influence the natural enemies especially parasitoid and predators. Consequently, they increase longevity and fecundity of parasitoid and predator that help to control insect pest. One of the most important recently used methods is push-pull which consists of semiochemicals called Herbivore-Induced Plant Volatiles (HIPVs). This compound has been used to prevent pest and attract natural enemies.
\end{abstract}

\section{Keywords}

Biological Control, Insect Pests, Habitat Management

\section{Introduction}

Enhancement of natural enemies (parasitoid, predator and weed feeder) through habitat management is concerning issue of the scientist for the control of insect pest. Invertebrate class of insects belongs to the phylum of arthropod. About 30 insect orders are currently used to classify the insect species of the world. The species of insects are about 750,000 under the hexapoda class. About 37 harmful insects are classified that are considered the most severe pest organisms. The major agricultural harmful insects are American oil beetle, aphids, blister beetle and boll weevil etc. which are responsible for causing large amount of crop loss. 
In Brazil annual average yield loss was $7.7 \%$ in production, which declines around 25 million tons of fibre, food and biofuel and in terms of economic loss it is approximately US\$17.7 billion [1].

For decreasing crop production, various types of insect pest control approaches are recognized in the last century namelybiological, physical, chemical as well as mechanical control. Chemical control has adverse effects on the environment as well as human health. Besides, environments are polluted by using chemical pesticide called "persistent organic pollutants" (POPs). Continuous application of pesticide causes pesticide resistance in insects. Different types of diseases like nervous systems, cancer and reproductive problems rose due to use of chemical pesticide. The important elements of integrated pest management (IPM) are biological control that basically controls of insects on the basis of parasitism, herbivory, predation and other natural mechanisms [2]. Biological control is an element of an integrated pest management method. It is involved the use of living organisms to reduce pest populations lower damaging levels [3] [4] [5]. Naturally occurring organisms and environmental factors, often without human input, help to suppress all insect species. This is also considered as natural control. This strategy involves the biological control of insects. Biological control included plant diseases and weeds which consisted of insects and pathogens. Biological control agents are also referred as natural enemies of insect pests, including predators, parasitoids as well as pathogens. Biological control agents of plant diseases are frequently called as antagonists. Biological method is the best for controlling insect pest because it has no adverse effects on the environment as well as comes with relatively low costs. Types of biological methods are effective for controlling of insect pests; such as conservation (Habitat management), classical and augmentation [6]. The most important as well as readily available biological control is conservation of natural enemies. It is easily available to the growers in the world. From the backyard to the commercial field, all production systems happened by natural enemies. Their conservation is naturally simple and cost effective as they are established to the local environment as well as to the target pest. The activity of the natural enemies can be found with generally little effort. These natural controls are essential and need to be preserved as well as considered to make pest management decisions. Each effort should be made to utilize a selective material in a selective manner, when an insecticide is needed. We need to classical biological control to obtain the natural enemies. This strategy is practiced for establishment of importing, and releasing natural enemies. Natural enemies are thus, used to control an introduced as well as native insect pests. In this process the first step is to identify the introduced pest origin and after that collect accurate natural enemies connected with the pest or closely related species. The natural enemies then are approved by a rigorous quarantine process so that the unwanted organisms (such as hyperparasitoids) are not introduced. They are reared therefore, for getting ideally large numbers, and released. Classical biological control is inexpensive as well as long 
lasting. Little expense is incurred beside the initial costs of collection, importation, as well as rearing. When a natural enemy is completely established it does not require additional input as well as without direct humans help and at no cost, it continues to kill the pest. Augmentation is the third type of biological control that includes the additional release of natural enemies. It is the one kind of biological control that are usually used for controlling of insect pest. The method basically used in commercially to reduce population density or to suppress a pest population. Another name of augmentation is habitat or environmental manipulation. Habitat management is a form of conservation biological control which has contribution to introduce of natural enemies to environment for increasing their fecundity, longevity, survival as well as behavioural. This strategy comprises diverting the cropping system to augment or influence the effectiveness of a natural enemy. Many adult parasitoids as well as predators are benefited through nectar sources. In addition, the refuges such as hedgerows, weedy borders as well as cover crops are used to protect them. Home gardens as well as small-scale commercial plantings are suitable place to incorporate augmentation, but large-scale crop production is more difficult to accommodate it. The diversity of the habitats is increased through mixed plantings and the provision of flowering borders. They also used as a shelter and alternative food sources. A long history of successes was observed in classical and augmental biological control of insect pests and weeds. Among these methods, habitat management is the most effective for controlling insect pest in agricultural systems.

Recently, scientists emphasize on the insect pest control through the habitat management. This method could be effective and economically save to control the specific pest below its economic threshold while it would be applied at proper time of the crop and pest phenology. Such conservation acts as an instructor for falling damaging effects and inducing appropriate condition. Habitat management increases the natural enemies through supply of food, shelter and ensuring of available prey. In addition, declining death, giving additional reserves, leading secondary enemies or familiarizing plant host traits that prompting of natural enemies could be controlled by conservation tactics [7]. Consequently, insect pest could be controlled by influencing natural enemies through habitat management. Diverse cropping systems, vegetation such as field margins and shelter belts are used for controlling insect population.

The ecology of natural enemies and particular pests and their appropriate environment in which they grow directly associated with habitat management. Habitat management influences the natural enemies through providing food, hibernation site, shelter and suppress the pests through arranging hedgerows, weed margin and alternative prey. Various forms of agricultural strategies such as crop rotation, intercropping, tillage are using for growing of natural enemies mainly predator and parasitoid that aids to suppress insect pest. The research question of my essay is how habitat management to enhance natural enemies and the effects of habitat management to suppress harmful insect pest in agri- 
cultural crops.

\section{Effects of Landscape Composition on Natural Enemies and Pest Pressure}

Different types of lands are remained in agriculture. The features of landscape have great effect on insect pest prevalence and control through applying natural enemies. Insect pest could be controlled by using landscape management. Primary production, herbivores and natural enemies are influenced by landscape context. Basically, the composition of landscape affects the pest abundance directly through its spreading, reproduction or indirectly by disturbing its natural enemies. Besides, the diversity and abundance of the natural enemy complex is affected by landscape composition. However, a broad diversity of natural enemies was found in a diversified agricultural landscape mosaic. The non-crop habitats dense with networks of complex landscapes provide suitable conditions and basics for natural enemy populations. As a result, the activity of natural enemy is enlarged in crop fields. In semi natural areas, landscapes showed higher density of pests or greater control of pests in fields. Thus, in the adverse condition, agricultural landscape also provides shelter, hosts or alternative prey [8].

Diversified landscape increased the higher and more diverse of natural enemy population resulting in increasing insect pest control. Besides these, it also helps to reduce pest population, reducing damage level and increasing yield or quality. Insect pest control function as well as biodiversity conservation is also potentially influenced by diversified landscape. The population of natural enemy as well as pest pressure in crops is also influenced by patchiness of the landscape. The results were reported from 24 studies that landscape composition improved natural enemy populations in 74\% [8]. In addition, higher percentage population of natural enemy and less amount of pest pressure was observed. Complex patchy landscape influenced more natural pest control than simple large scale landscape.

\section{Effects of Plant Characteristics on Natural Enemy}

Plant characteristics are the important resources of habitat management that enhance the natural enemies and suppress the insect pest. Plants provide shelter, food, nectar and pollen that directly influence natural enemies. Parasitoids host selection is influenced by the insect parasitoid that contributes by the nature of plants in terms of ecology and biology. The most important things of non-pollinating insects such as biological control agents are flowers. The color of flowers is not only the important characteristics for insect identification but also for pollination biology. Flowering color is a most important factors for influencing natural enemies. It was reported that white flower color influenced more than purple, dark pink and light pink color [9]. Besides, the natures of plants used for improving biocontrol rely on flower color as well as it also has unlimited contribution in parasitoid. The natural enemies of insects influenced to 
floral attraction by accessibility and duration of flowering. The studies which are conducted with cotton, cabbage, corn, beans have indicated that the host locating prompts which are used for parasitoids coming from the plant's products.

However, flowering plants increased the damage of crops. Therefore, for enhancing biological control, flower color in case of plants is the essential factor that enhances the natural enemies and suppresses pest population. The characteristics of plants such as pollen and nectar influence fecundity, survival, abundance of natural enemies [10]. Excess nectar and pollen are required for many parasitoids and insect predators. For increasing natural enemies especially predators and parasitoids require non prey food such as pollen, nectar as their diet for their survival. These non-prey food with flowering plants, will supply essential elements that protect the parasitoids and predators throughout the season. Thus, pollen and nectar help to increase the population of natural enemies by providing their food. Moreover, survival, longevity, fecundity as well as level of parasitism are also influenced by the availability of food.

Plant structure acts as a protector against herbivores. In several ways, parasitoids could be affected by planting structures and plantmorphology. Parasitoid penetrating on the base of waxy leaf surfaces, surface area leaf toughness, glandular trichomes and foliar pubescence. Parasitoid mortality raised due to hairy leaves that retained honeydew and the spending time for grooming of parasitoid will be rising. The predators which are used for controlling of insect pest are influenced by the plant characteristics. Predators are influenced by potentiality of the morphology of plants directly or indirectly on the basis of availability and type of herbivores on a plant. Even small changes of plants also affect differentially of the predators when they remain in different cultivar. The ability of predators to look and capture of prey are also influenced by the plant surfaces. The effectiveness of predators depend on the morphological traits such as nature, density and presence of trichomes. For instance, Predator Orius insidiosus (say), Hippodamia convergens, Guerin meneville and Chrysoperla carnea (Stehens) helps to decrease prey population which found on glossy surfaces of cabbage cultivars rather than standard usual wax variety [11]. In addition, the utilization, survival and performance of predators depend on plant structure. For example, the existence of domatia confirms for greater amount of mites and offer accommodations for predatory mites.

The surfaces of plants along with microclimate can be influenced by plants and plant parts, for example, the leaves of upper warmer than lower leaves. The oviposition sites and dispersion pattern of herbivores are affected by these differences. For instance, the underneath of leaves are suckling by the early instars of Pieris brassicae (L.), while the external of the leaves are feeding by the old instars, on the same plant. The plants emit fragrant signals, when affected by insect herbivores that help to occurrence natural enemies. It also reported that when plant species affected by different and various stages of herbivores resulting in produced plant volatiles. The generalist and specialist parasitoids respond to 
different plant volatiles. These compounds are produced from both in the entire plants gradually as well as damaged sites. Thus, when the plant attacked by the herbivore produced lots of chemical signals that traps the parasitoids. The plants varieties with desired characteristics could be used for enhancing the efficiency of plant parasitoid; for example, parasitoids are attacked by large amount's compounds of volatiles which secreted by plants. For instance, cotton plants produced these vital volatile compounds.

The leaves and flowers of cotton plants secreted smells that attacked by the parasitoid Campoletis sonorensis. The particular glands that deposited terpenoids volatiles usually involved in the attraction. Wild cotton varieties formed large amounts of terpenoids than commercial cultivars was observed [12]. Besides this, the nutrients as well as allelochemicals form of plant chemistry may also influence the longevity, fecundity, survival, size, development and sex ratio of parasitoids. Immature parasitoid directly could be affected by the plant chemistry when the developing parasitoid adversely affected by the toxic substances that produced from the host. Thus, plant chemistry play an important role for increasing natural enemies especially parasitoids.

The immune response of herbivores could be interfered with different plant quality; the eggs of parasitoid affected by it. Parasitoids indirectly could be affected by nutritional quality variation of plants, when it would be increased during development time of herbivore. The hosts, particularly, at certain stages are affected by parasitoids. Plant traits which have great positive and negative impact on natural enemies showed resistance against herbivore. Different studies indicated that parasitoid attacks more herbivores on the basis of some plant cultivars feeding as well as plant cultivars also influence the parasitoid performance among hosts. All natural enemies of insects are not beneficial to crop production. The life cycles and behaviors of natural enemies can be simple or additional complex. For instance, hyperparasitoids are parasitoids of other parasitoids. A large reproductive rate is essential so that populations of the natural enemy can quickly increase when hosts are present in large amount. At searching, the natural enemy must be effective for its host as well as only one or a few host species are searched for it. For instance, many various hosts including other natural enemies are feed by it. It is also very essential that the occurrence of the natural enemy should be similar as its host. For instance, when host eggs are present, the natural enemy is an egg parasitoid should be available. All these attributes are not present in natural enemy, but those with some characteristics will be more essential in balancing pest populations.

\section{Habitat Enhancement and Conservation of Natural Enemies}

The nature of the habitat in terms of flexibility of its flora and fauna, longevity, structure, composition and texture dictated greatly by the life cycle of crop plants. As a result, diversity decreased in local habitat. The abundance and effi- 
ciency of natural enemies could be affected seriously by habitat enhancement. The natural enemies rely on habitat complexity for shelter, nesting, overwintering, alternative prey or hosts as sources. Diversified agro systems of plants increased the opportunities of environment for natural enemies resulting in enhanced biological control.

Non-crop habitats which are fallows (set aside land), field margins, wood lots and hedgerows are moderately undisturbed as well as the area which are temporally permanent hold the agricultural landscapes in considerable proportion. Plants, insects, birds and mammals used for biodiversity reservoirs that indicated by these habitat [13]. Non crop habitats are major source of natural habitats and use as source habitats resulting in the suitable fields of agriculture are less invaded. When natural enemies used non crop habitats in a year round act as a sink in comparison to crop habitats. The natural enemies used noncrop habitats as a reservoir resulting in an increased population of natural enemy. Insect pest attacked could be reduced by means of habitat management through improve of third trophic level (natural enemies) through functioning the effects of top down control. Moreover, the first trophic level (flora) of diverse habitats aid to decline of pests by working the effects of bottom up.

\section{Agronomic Practices}

\subsection{Adjusting Planting Time and Space}

Planting time adjustment of agricultural crops is an important technique to save them from insect pest through keeping them away from the active season of pest. This can be done by waiting for a suitable period instead of growing crops in time. It is a process of avoidance of insects so that crops protected from the insect pest infestation. The infestation of insects could be reduced through adjusting of planting and harvesting dates. For instance, the infestation rate of black cutworms in corn reduced due to early planting. In case of soybeans, the infestation of seedcorn maggots decreased due to late planting. Conversely, at the early first cutting of alfalfa, the infestation alfalfa weevil could be reduced through supply more predators, dry conditioning and explosion to more sunlight.

\subsection{Crop Rotation}

The most effective tool for controlling insects is crop rotation. The pests which have no ability to move, have to affinity for feeding specific crops as well as remained as egg in soil during overwinter or larvae that grown partially could be easily handled through crop rotation. The problems of insect pests have been accelerated due to crop monocultures. Insect pest population could be reduced by crop rotation through soil improvement. Western corn root worm larvae are vulnerable to crop rotation of alfalfa. For this reason, crop rotation would be an actual way for controlling corn pest. Diverse cropping systems of plant could be designed in various ways that affect the insect population, agronomically. The manipulation of vegetation affects the insect's population through field margins, 
species composition managing and other types of shelter belts. Moreover, insect dynamics is greatly influenced by the weed diversity, which remains in form of weed borders, alternate rows or supply weeds certain period of crop growth.

\subsection{Cover Crops}

Cover crops play a vital part not only for governing of insect pest but also decline hold soil nutrients, reduction soil compaction, soil erosion as well as produce organic matter. It basically harbors those insect pests which are harmful to the crops. On the other hand, natural enemies get shelter and resources from the cover crops resulting in decrease insect pest. The dispersion of cover crops within the perennial crops make a problem insecticide based pest management activities that suppress the natural enemies which remain in the field. Flowering cover crops is one component of farms aping that make farmland appropriate natural enemies in the whole growing season. More natural enemies were found particularly parasitoids in apple orchards connected with flowering borders than without flowering borders. Significant quantities of residue and surface vegetation are created by covering crops that can be achieved to increase control of pests. For instance, soil-dwelling herbivores namely colorado potato beetle suppressed by the cover crops through disturbing migration behavior and emergence resulting in increasing yield. Cover crops attack the pest's capacity for colonize hosts by disrupting olfactory, visual cues, arresting physical barriers and generating diversions to noncrop hosts. Moreover, cover crops also destroy the established pest population by disrupting feeding, increasing mortality, inhibiting the reproduction and reducing dispersal from parasitoids and predators [14]. Conversely, cover crops with diversified agroecosystem decreased pest population in a similar way. Cover crops with conservation tillage decrease this regular disruption and help to enhance year round natural enemy and pest species interactions by supplying another hosts or prey as well as protection from adverse conditions. Thus, cover crops help to promote natural enemies and suppression of pest.

\subsection{Intercropping}

Intercropping consists of multiple cropping systems in which two or more crops are grown at the same time in the growing season. It was reported by [15] that number of natural enemies and their richness are greatly influenced by intercropping resulting in wider reduction of pest species. Intercropping helps to reduce insect pest and increases natural enemies resulting in increased yield. It was observed that intercropping reduced pest and increased pest 53\% and 18\% experiments respectively, in comparison of the pure cropping [16]. The major pests such as Pseudococcus comstocki, Aphis citricola, and Psylla chinensis remarkably decreased due to intercropping whereas the numbers of their natural enemies (Phytoseiulus persimilisand, Coccinellan septempunctata and Chrysoperla sinica) enlarged and their frequency period late at varying degree. For instance, 
arthropod pest management could be improved considerably through intercropping including aromatic plants by influencing the community activity of valuable arthropod. One study about peach orchards of intercropping white clover indicated that the reduction of pest incidence resulting from increasing diversified arthropod community as well as natural enemies. Natural enemies also influenced by intercropping aromatic plants. In orchard ecosystems, intercropping would be more effective for pest management when the relationship between arthropods and aromatic plants remained. Intercropping crop plants along flowering species namely clove provide a suitable habitat for various natural enemies for biological control in the agroecosystems that helps to manage of natural pest.

\subsection{Tillage}

Tillage has a great impact for increasing natural enemies and decreasing pest population. Tillage frequency, tillage types, tillage intensity influence the natural enemies and pest suppression. Particularly, less the amount of tillage affects the diverse species through providing a stable environment. The diversity of fauna and their availability depends on the tillage. The effects of tillage depend on the species to species and particularly their ecological characteristics. For instance, mostly pupal stage and larvae of a species which remain in soil are more vulnerable to tillage. A study was carried out by [17] reported that when parasite remained in soil during overwintering in the next spring, the rate of emergence reduced due to post harvest tillage. Proper application of tillage has a great impact on pest nematode management. The densities of plant-parasitic nematodes are greatly influenced by tillage practices. The number and types of insects are suppressed by reducing tillage or conservation tillage. The variation of conservation tillage has the potentiality to suppress specific pests. At the beginning of the reducing tillage influence the practices of basic pest management. Conservation tillage has great impact on insects. The higher amount of predator communities and $16 \%$ aphid predation more than in the field managed supported by conservation tillage [18]. It also enlarged the aphid parasitism rate. Under the condition of tillage conservation, vegetation of aphid predation and ground dwelling of arthropods were raised. Many insects destroyed through exposing them in weather and birds by deep ploughing. Besides this, many insects are hindered in soil physically.

\subsection{Push-Pull Strategy}

Push pull strategy is one kind of recently developed strategy for controlling insects in which crops are protected from the insect (push) and trap crops are attacked by them (pull). The term of Push pull strategy was first introduced in Australia for insect pest management (IPM) [19]. The main characteristics of push pull strategy are efficiency, control efficiency, stability and without any environmental hazard. Moreover, the systems were found in Africa for sustainable 
agriculture. The Push pull strategy plays an important role in controlling stemborer. In this method, insects discharge two kinds of semiochemical when plants are damaged by herbivore such as ocimens and nonatriene. These compounds are responsible for highly stem borer colonization and used by parasitoids for foraging, would be repulsive to ovipositing stemborers. The components of push and pull are generally nontoxic and therefore, biological control connected with this strategy. In this tactics, the pests attract traps or trap crops to another area where they are detected and improving their control through spending attractive and highly motivations. In this strategy, plants are used combinedly as trap crops as well as intercrops that are suitable for the farmers. Recently, push pull strategies are being used by about ten thousand people to prevent cereal stemborer of maize and sorghum in eastern Africa. Agrobiodiversity and chemical ecology are exploited through push-pull strategy. In this method under plant chemistry, the trap plants secrete attractive volatiles and intercrops release repellent volatiles for control stem borer. Both gas chromatography (GC) and electroantennography that remain the antennae of stem borers and their natural enemies help to identify volatile chemicals which release from repellent and trap plants under the push pull ecology system. One experiment that was conducted by [20] showed that the reduction of damage in maize crops which occurred by stem borer ranged from $39.2 \%$ to $4.6 \%$, whereas significantly higher level of stem borer was found in maize in that case $16.8 \%$ and $27.5 \%$ stem cutting and larval mining respectively, in the treatment as well as control plots, respectively.

\section{Discussion}

Recently, scientists are concerned on habitat management which has great contribution for increasing natural enemies and controlling the density of pest population. Considering this, to protect agricultural crops from the insect pest damage under habitat management is alarming issue for the whole world. To increase agricultural production in addition of environmental safety, habitat management is an unreplaceable factor for conserving natural enemies as well as reduction of insect pest. The habitat management is influenced by the landscape composition, nature of plants, flower color, longevity of flowers, non-crop habitats such as weedy lots, hedgerow, field margins. The appropriate infrastructure of ecology created through the habitat management within agricultural landscapes which supply resources such as food for adult natural enemies. Ecosystem services as well as functional biodiversity have a great importance for controlling pest density through habitat management. In an agroecosystem, diversified plants and other organisms have closely positive relationship with physically diversified habitats.

Natural enemies especially parasitoids and predators are effective tool for controlling insect pest through habitat management. The natural enemies may seek refuge or hibernate in the condition of environmental extremes or pesticides by providing shelter, developing the availability of alternative foods such as 
honeydew, pollen and nectar. It has also a major contribution to ecological theory and modelling of biological control, conservation especially in the developing area. Natural enemies could also be benefited by food sprays, but this method could be applicable only for those crops which are economically demandable. The important food basis of natural enemies is another host or prey as well as housing. Besides this, pollen, nectar and honey dew are also used for natural enemies. Plant characteristics such as flower color, duration of flower also influence insect pest control. Moreover, plant phenotypic characteristics such as density, nature, and presence of trichomes has important role for growing natural enemies and reduction of insect pest. Recently, the use of pesticide has decreased due to the using of biological control. Moreover, decreasing the use of a pesticide for minimizing the negative effects of natural enemies. At present, conservation practices have been increased for changing the natural enemies' habitat. The recent literature showed that the impact of arthropods parasites and predators of arthropod pests enhanced by the practices of habitat management.

At present various types of agricultural technologies are used to increase natural enemies as well as insect pest control. Adjusting planting time as well as space could be used for controlling insect pest. Conservation tillage, cover cropping, crop rotation as well as intercropping are fruitful agricultural practices which enrich the population of natural enemies through providing proper environment. Intercropping greatly enhanced the amount of natural enemy resulting in increasing of pest population. For protecting the crops from the insect, the most effective biological method is push pull strategy. Semiochemical secreted from the herbivore insects which prevent insect and attack natural enemies. This strategy has no adverse effects on environment and generally non-toxic. Biological control will have great contribution to the crop protection industry in future. The efficacy as well as successful outcome of the commercial product depends on the appropriate formulation and application tactics. Genetic engineering may be used as effective tools to increase the biological control efficacy. This strategy, an essential component of an integrated disease management scheme, is involved in a significant and permanent reduction of pesticide use. This method also used as cheaper than other methods. Though, the speed of change is not fast, the next crop protection challenge will be addressed by the innovation of biological control industry in the future. Biological control plays a vital role in improving communication of environmental, economic and social success as well as for insect pests, weeds and plant diseases, regulatory, targeting political, land/grower manager as well as stakeholder interests. However, biological control strategies have not been generally accepted or universally utilized as they could be. Recently, scientists have done research on the biological control of insect pest through exploration of habitat management. The major limitation was observed in landscape composition, crop rotation as well as plant characteristics but major work was done on the push-pull strategy. Moreover, research on mode of natural enemies is very limited. Considering this, more research on be- 
haviour of natural enemies as well as their effects on insect pest suppression could be needed in future.

\section{Conclusion}

Proper habitat management decreased the pest population under the economic threshold level through enhancing the activities of natural enemies. Although, habitat management is a good agricultural practices, it's not acceptable to the farmers due to delay effectiveness. So, the application of the habitat management should be expanded among the farmers. Considering all, more research should be conducted on the habitat management for saving agricultural crops from insect pest in future.

\section{Conflicts of Interest}

The authors declare no conflicts of interest regarding the publication of this paper.

\section{References}

[1] Oliveira, C.M., Auad, A.M., Mendes, S.M. and Frizzas, M.R. (2014) Crop Losses and the Economic Impact of Insect Pests on Brazilian Agriculture. Crop Protection, 56, 50-54. https://doi.org/10.1016/j.cropro.2013.10.022

[2] Hoy, M.A. (1994) Parasitoids and Predators in Management of Arthropod Pests. Introduction to Insect Pest Management, 4, 129-198.

[3] Altieri, M.A., Nicholls, C.I. and Fritz, M.A. (2005) Manage Insects on Your Farm: A Guide to Ecological Strategies. SARE Outreach, College Park.

[4] Mahr, D.L. and Ridgway, N.M. (2008) Biological Control of Insects and Mites: An Introduction to Beneficial Natural Enemies and Their Use in Pest Management. North Central Regional Extension, SARE Outreach, College Park.

[5] Ward, M.J., Ryan, M.R., Curran, W.S., Barbercheck, M.E. and Mortensen, D.A. (2011) Cover Crops and Disturbance Influence Activity-Density of Weed Seed Predators Amara aenea and Harpalus pensylvanicus (Coleoptera: Carabidae). Weed Science, 59, 76-81. https://doi.org/10.1614/WS-D-10-00065.1

[6] Van Lenteren, J.C. (2012) The State of Commercial Augmentative Biological Control: Plenty of Natural Enemies, but a Frustrating Lack of Uptake. BioControl, 57, 1-20. https://doi.org/10.1007/s10526-011-9395-1

[7] DeBach, P., Huffaker, C.B. and MacPhee, A.W. (1976) Evaluation of the Impact of Natural Enemies. In: Theory and Practice of Biological Control, Academic Press, Cambridge, 255-285. https://doi.org/10.1016/B978-0-12-360350-0.50017-9

[8] Bianchi, F.J.J.A., Booij, C.J.H. and Tscharntke, T. (2006) Sustainable Pest Regulation in Agricultural Landscapes: A Review on Landscape Composition, Biodiversity and Natural Pest Control. Proceedings of the Royal Society of London B: Biological Sciences, 273, 1715-1727. https://doi.org/10.1098/rspb.2006.3530

[9] Begum, M., Gurr, G.M., Wratten, S.D. and Nicol, H.I. (2004) Flower Color Affects Tri-Trophic-Level Biocontrol Interactions. Biological Control, 30, 584-590. https://doi.org/10.1016/j.biocontrol.2004.03.005

[10] Cortesero, A.M., Stapel, J.O. and Lewis, W.J. (2000) Understanding and Manipulating Plant Attributes to Enhance Biological Control. Biological Control, 17, 35-49. 
https://doi.org/10.1006/bcon.1999.0777

[11] Legaspi, J.C., Nordlund, D.A. and Legaspi Jr., B.C. (1996) Tri-Trophic Interactions and Predation Rates in Chrysoperla spp. Attacking the Silverleaf Whitefly. The Southwestern Entomologist, 21, 33-42.

[12] Loughrin, J.H., Manukian, A., Heath, R.R. and Tumlinson, J.H. (1995) Volatiles Emitted by Different Cotton Varieties Damaged by Feeding Beet Armyworm Larvae. Journal of Chemical Ecology, 21, 1217-1227. https://doi.org/10.1007/BF02228321

[13] Van Buskirk, J. and Willi, Y. (2004) Enhancement of Farmland Biodiversity within Set-Aside Land. Conservation Biology, 18, 987-994. https://doi.org/10.1111/j.1523-1739.2004.00359.x

[14] Teasdale, J.R., Abdul-Baki, A.A., Mill, D.J. and Thorpe, K.W. (2002) Enhanced Pest Management with Cover Crop Mulches. XXVI International Horticultural Congress. Sustainability of Horticultural Systems in the 21 st Century, 638, 135-140.

[15] Beizhou, S., Jie, Z., Jinghui, H., Hongying, W., Yun, K. and Yuncong, Y. (2011) Temporal Dynamics of the Arthropod Community in Pear Orchards Intercropped with Aromatic Plants. Pest Management Science, 67, 1107-1114.

https://doi.org/10.1002/ps.2156

[16] Francis, C.A. (1989) Biological Efficiencies in Multiple-Cropping Systems. Advances in Agronomy, 42, 1-42. https://doi.org/10.1016/S0065-2113(08)60522-2

[17] Ferguson, A.W., Campbell, J.M., Warner, D.J., Watts, N.P., Schmidt, J.E.U. and Williams, I.H. (2003) Spatio-Temporal Distributions of Meligethes aeneus and Its Parasitoids in an Oilseed Rape Crop and Their Significance for Crop Protection. Proceedings. 11th International Rapeseed Congress, Copenhagen, 6-10 July 2003, 1057-1059.

[18] Tamburini, G., De Simone, S., Sigura, M., Boscutti, F. and Marini, L. (2016) Conservation Tillage Mitigates the Negative Effect of Landscape Simplification on Biological Control. Journal of Applied Ecology, 53, 233-241. https://doi.org/10.1111/1365-2664.12544

[19] Pyke, B., Rice, M., Sabine, B. and Zalucki, M.P. (1987) The Push-Pull Strategy-Behavioural Control of Heliothis. Australian Cotton Grower, 9, 7-9.

[20] Khan, Z.R., Ampong-Nyarko, K., Chiliswa, P., Hassanali, A., Kimani, S., Lwande, W. and Woodcock, C.M. (1997) Intercropping Increases Parasitism of Pests. Nature, 388, 631-632. 